\title{
Does Hearing Impairment Affect Mental Health Among Chinese Older Adults? Evidence from the Chinese Longitudinal Healthy Longevity Survey
}

This article was published in the following Dove Press journal: Risk Management and Healthcare Policy

\author{
Jian Sun' \\ Hongheng $\mathrm{Li}^{2}$ \\ Ling Jin ${ }^{3}$ \\ Hongye Luo ${ }^{2}$ \\ 'School of International and Public \\ Affairs, Shanghai Jiao Tong University, \\ Shanghai, People's Republic of China; \\ ${ }^{2}$ School of Information and Management, \\ Guangxi Medical University, Nanning, \\ Guangxi Zhuang Autonomous Region, \\ People's Republic of China; ${ }^{3}$ Liuzhou \\ People's Hospital, Liuzhou, Guangxi \\ Zhuang Autonomous Region, People's \\ Republic of China
}

Correspondence: Hongye Luo School of Information and Management, Guangxi Medical University, Nanning, Guangxi Zhuang Autonomous Region, 53002I, People's Republic of China Tel +86-139-7883-I304

Email hongye283@163.com
Background and Aim: Hearing impairment is a commonly reported chronic condition among older adults. Hearing impairment is significantly associated with reduced quality of life and diminished function status. This study aimed to investigate the association between hearing impairment and mental health among Chinese older adults, with a focus on exploring the moderating effects of social participation and exercise on this association.

Methods: The data of this study were obtained from the 2018 wave of Chinese Longitudinal Healthy Longevity Survey (CLHLS). We employed ordinary least squares regression models to analyze the effect of hearing impairment on mental health. Propensity score matching (PSM) and doubly robust estimation were employed to conduct robustness checks.

Results: Hearing impairment produced an adverse effect on Mini-Mental State Examination (MMSE) score (coefficient $=-1.4073, p<0.001$ ), while it had a positive effect on depression score (coefficient $=0.8682, p<0.001$ ). Further analyses using PSM and doubly robust estimation reported similar results. Moreover, social participation (coefficient $=0.9424, p<$ 0.001 ) and exercise (coefficient $=0.7001, p<0.01$ ) moderated the association between hearing impairment and MMSE score. Social participation (coefficient $=-0.5991, p>0.05$ ) and exercise (coefficient $=0.7806, p>0.05$ ) did not moderate the association between hearing impairment and depression score.

Conclusion: We provide robust evidence indicating that hearing impairment had significantly negative effects on the cognitive function and depression status of older adults. Furthermore, we find that social participation and exercise relieved the negative effect of hearing impairment on cognitive function.

Keywords: hearing impairment, mental health, social participation, exercise, China

\section{Introduction}

Hearing impairment is a commonly reported chronic condition among older adults. A study indicates that about $11 \%$ of older adults who aged 60 and above in China were diagnosed with hearing impairment. ${ }^{1}$ Furthermore, a study suggests that hearing impairment can impair the exchange of information, ${ }^{2}$ thus hearing-impaired elderly people are more likely to have smaller social networks. ${ }^{3}$ Moreover, hearing impairment is significantly associated with reduced quality of life and diminished function status. ${ }^{4-8}$ Wearing hearing aid is a common intervention to treat hearing impairment. ${ }^{9}$ A study reported that people who wear hearing aids manifested better health outcomes. $^{10}$ 
With the significant increase in life expectancy and decrease in birth rate, population aging has become an important social issue in China. In 2018, the number of Chinese older adults who aged 65 and above reached 166.58 million, accounting for $11.9 \%$ of its total population. ${ }^{11}$ The ageing trend of China will continue to accelerate in the next few decades. ${ }^{12}$ The health outcome of older adults has become an important issue in Chinese society. Mental health is an important part of heath outcome. In a society with a large number of older adults, it is of great significance to analyze the factors that influence their mental health and formulate relevant intervention approaches. Due to the changing social roles and decrease in social interactions, older adults are more likely to have negative emotions. ${ }^{13}$ In addition, with the gradual decline of physiological function, older adults have a higher incidence of dementia, depression, and other mental diseases. ${ }^{14}$ Furthermore, older adults are more likely to experience some negative life events, such as bereft of spouse and retirement, which will have significantly negative effects on their mental health. ${ }^{15}$ Moreover, in order to improve the health outcome of older adults, the Chinese government attaches great importance to the construction of healthy aging. The 13th Five-Year Planning for Healthy Aging which was issued by the Chinese government in 2017 states that it is of great importance to promote health promotion and education, strengthen public health services, improve the health care services system, and strengthen the medical security system to achieve healthy aging.

Previous studies have analyzed the effect of hearing status on mental health. Some scholars have investigated the effect of hearing impairment on cognitive function. A study which is conducted by Dalton et al indicates that hearing impairment is significantly associated with impaired cognitive function. ${ }^{4}$ Tan and Chen employed the 2015 wave of China Health and Retirement Longitudinal Survey (CHARLS) dataset and found that hearing function was positively associated with cognitive function of older adults. ${ }^{16}$ Gao et al used the fixed effects regression models and reported that hearing status significantly affected the cognitive function of older adults. ${ }^{6}$ In addition, some scholars have explored the effect of hearing impairment on depression status, while they did not reach a consensus. Strawbridge et al used longitudinal data and contended that older adults with hearing impairment were more likely to be depressed when compared with those without hearing impairment. ${ }^{17}$ Keidser and Seeto reported that hearing impairment was significantly related to more depression symptoms among older adults. ${ }^{18}$ Ye et al used the 2015 wave of CHARLS dataset and reported that hearing impairment significantly affected older adults' depression status which was measured by the 10-item Center of Epidemiological Survey-Depression (CES-D) scale. ${ }^{19}$ However, some studies reveal that hearing impairment was not significantly associated with the prevalence of depression symptoms among Chinese older adults. ${ }^{20,21}$

Previous studies indicate that social participation had a significantly positive effect on mental health. ${ }^{22-24}$ Furthermore, some studies suggest that exercise produced a significantly positive effect on mental health. ${ }^{25-28}$ Hearing impairment may produce a weaker and negative effect on the mental health of the hearing-impaired people who participated in social activities and exercise when compared with those who did not participate in social activity or exercise. Consequently, we hypothesized that participation in social activities and exercise may play significant roles in the association between hearing impairment and mental health.

Overall, we find that a very limited number of studies have been done to explore the moderating effects of social participation and exercise on the association between hearing impairment and mental health among Chinese older adults. To overcome these research gaps, this study used the data which was obtained from the 2018 wave of Chinese Longitudinal Healthy Longevity Survey and aimed to investigate the association between hearing impairment and mental health among Chinese older adults, with a focus on exploring the moderating effects of social participation and exercise on this association. We will use propensity score matching and doubly robust estimation to conduct robustness checks. The results of this study can shed more light on the understanding of the effect of hearing impairment on mental health among the older adults in China, and provide some references for formulating intervention approaches to improve their mental health.

\section{Methods \\ Data Source}

The data of this study were obtained from the 2018 wave of Chinese Longitudinal Healthy Longevity Survey (CLHLS). This survey was conducted by Center for Healthy Aging and Development at Peking University. The CLHLS has been conducted for 8 waves. The first 
wave data of CLHLS were collected in $1998,{ }^{29}$ and the 2018 wave is the latest wave data at the time of this study. As a nationally representative survey, the CLHLS covers 23 provinces of China. Furthermore, its purpose is to shed more light on the determinants of healthy human longevity and oldest-old mortality in China. Considering the fact that the CLHLS includes enough information regarding hearing impairment, mental health, social participation, exercise, demographic characteristics variables, and socioeconomic status and social support variables of Chinese older adults, we employed it to explore the effect of hearing impairment on mental health. Moreover, because this study focused on the effect of hearing impairment on mental health among older adults, respondents were removed if they aged less than 65. After deleting observations with missing information regarding the above-mentioned variables, a total of 3721 older adults who aged 65 and above were included in this study, which includes 1706 females and 2015 males.

\section{Variables \\ Dependent Variables}

In this study, mental health is the dependent variable, and we employed two methods to measure it. Firstly, we used the Chinese version of Mini-Mental State Examination (MMSE) scale to measure the cognitive function of older adults. The Chinese version of MMSE scale was adapted from the scale which was originally developed by Folstein et al. ${ }^{30}$ Furthermore, some studies have confirmed that the Chinese version of MMSE scale has a good reliability and validity for Chinese older adults. ${ }^{31,32}$ Moreover, the Chinese version of MMSE scale is compromised of 24 easily understandable items, such as "what time of day is it right now?", "repeat a sentence", and "put paper on the floor". The Chinese version of MMSE scale captures seven dimensions of older adults' cognitive function (orientation, short-term memory, reaction, calculation, drawing, naming, and language). Most items have two responses, with correct answers coded as 1 and incorrect answers coded as 0 . We summed the MMSE items to get a total score for each older adult. The MMSE score ranges from 0 to 30, with a higher MMSE score indicating better cognitive function.

Secondly, we used the depression score to capture the depression status of older adults. The depression status was assessed by asking each older adult ten questions. Among the ten questions, eight of which were negatively oriented questions, such as "are you worried about some small things?", "is it difficult to concentrate when you are doing things now?", "are you feeling sad or depressed?", "are you nervous and scared?", and "do you feel lonely?"; two of which were positively oriented questions, including "are you full of hope for future life?", "do you feel as happy as you are when you are young?". All the ten questions have five response levels, which range from always (coded as 1), often (coded as 2), sometimes (coded as 3), seldom (coded as 4), to rarely or never (coded as 5). We then reverse-coded the negatively oriented questions, and they were measured by a 5-point Likert scale ("rarely or never" coded as 0, "seldom" coded as 1, "sometimes" coded as 2, "often" coded as 3, and "always" coded as 4). Furthermore, the positively oriented questions were also measured by a 5-point Likert scale ("always" coded as 0, "often" coded as 1, "sometimes" coded as 2, "seldom" coded as 3, and "rarely or never" coded as 4). In addition, the ten questions were summed to get a total depression score for each older adult. The depression score ranges from 0 to 40 , with a higher score suggesting a greater degree of depressed mood.

\section{Independent Variable}

In this study, hearing impairment is the independent variable, which was captured by asking the older adults "do you have any difficulty with your hearing?", with two possible responses: "Yes" and "No". "Yes" was coded as having hearing impairment, while "No" was coded as not having hearing impairment.

\section{Control Variables}

Based on previous studies, $, 33,34$ two types of control variables that were linked to mental health were selected in this study. The first type of control variables described the demographic characteristics, which include age (continuous variable), gender ( $1=$ male; $0=$ female $)$, marital status ( 1 = married; $0=$ single, divorced or widowed $)$, and residency area $(1=$ living in urban areas; $0=$ living in rural areas). The second type of control variables described the socioeconomic status and social support, which include years of schooling (continuous variable), household income (logarithm value), health insurance (1 $=$ with health insurance; $0=$ without health insurance), and number of children (continuous variable). In addition, a set of dummies for provinces were controlled in order to rule out the region fixed effects (with Beijing as a reference group). 
This study conducted a variance inflation factor (VIF) test, with test results indicating that the mean VIF value was 1.95 and all the VIF values of variables used in this study were much lower than the critical value of 10 , which reveals that there was no serious multicollinearity across the regression models.

\section{Moderators}

There are two moderators for this study, including social participation and exercise. Social participation is a dummy variable, which indicates whether the older adults took part in social activities or not (taking part in social activities coded as 1). In CLHLS, respondents were asked "do you take part in some social activities at present?" This question has five response levels, which range from "almost everyday", "not daily, but once for a week", "not weekly, but at least once for a month", "not monthly, but sometimes", to "never". We regrouped "almost everyday", "not daily, but once for a week", "not weekly, but at least once for a month", and "not monthly, but sometimes" as taking part in social activities, and regrouped "never" as taking part in no social activity. In addition, exercise is also a dummy variable, which reflects whether the older adults took part in exercise or not (taking part in exercise coded as 1). In CLHLS, respondents were asked "do you exercise or not at present?" The answers to this question are in a yes/no format.

\section{Statistical Analyses}

Considering the fact that the independent variables of this study were continuous variables, we employed ordinary least squares (OLS) regression models to analyze the effect of hearing impairment on mental health among the older adults. In addition, we used robust standard errors to alleviate the potential effect of heteroscedasticity. The specification of econometric model is as follows:

Mental health ${ }_{i}=\alpha_{0}+\alpha_{1} * H I_{i}+\alpha_{2} * C V_{i}+\delta_{s}+\varepsilon_{i}(1)$ where $i$ indicates individual, $H I_{i}$ denotes hearing impairment, $C V_{i}$ represents the control variables, which includes age, gender, marital status, residency area, years of schooling, household income, health insurance, and number of children, $\alpha_{0}$ stands for the intercept term, $\alpha_{1}$ is the coefficient of hearing impairment, which is our main interest, $\alpha_{2}$ indicates the coefficients of control variables, $\delta_{s}$ indicates the fixed effects of provinces, and $\varepsilon_{i}$ is the error term.

In addition, given the fact that propensity score matching (PSM) which is based on Neyman-Rubin counterfactual framework of causality can address the selection bias caused by observable individual heterogeneity, make observational data close to random trial data, and obtain robust estimation results, ${ }^{35-37}$ we employed it to conduct a robustness check. Furthermore, PSM is a nonparametric estimation method, thus it is not limited by the traditional linear model specification. ${ }^{38}$ In this study, logit regression model was employed to estimate propensity score.

Average treatment effect on the treated (ATT) was estimated as follows:

$$
A T T=E\left(Y^{T}-Y^{C} \mid D_{i}=1\right)=E\left(Y^{T} \mid D_{i}=1\right)-E\left(Y^{C} \mid D_{i}\right.
$$
=1) (2)

where $E\left(Y^{T} \mid D_{i}=1\right)$ suggests the average mental health of the older adults with hearing impairment, and $E$ $\left(Y^{C} \mid D_{i}=1\right)$ is the counterfactual outcome, which indicates what the average mental health of the older adults with hearing impairment would have been if they had not suffered from hearing impairment.

Doubly robust estimation combines propensity score weighting and regression model. ${ }^{38}$ If the propensity score weighting or regression model is correctly specified, a doubly robust estimator will produce an unbiased estimate of the average treatment effect. ${ }^{39}$ Doubly robust estimation has two estimation methods, including augmented inverse-probability weighting (AIPW) and inverseprobability-weighted regression adjustment (IPWRA). Given the fact that doubly robust estimation can provide robust estimation results, ${ }^{40}$ we used it to conduct a robustness check.

In this study, moderated multiple regression was employed to test moderating effects. To explore the moderating effect of social participation on the association between hearing impairment and mental health, we added the interaction of hearing impairment and social participation to Eq. (1). The specification of econometric model is as follows:

Mental health ${ }_{i}=\beta_{0}+\beta_{1} * H I_{i}+\beta_{2} * S P_{i}+\beta_{3} * H I_{i} * S P_{i}+\beta_{4}$ $* \mathrm{CV}_{i}+\delta_{s}+\varepsilon_{i}(3)$

where $H I_{i}$ denotes hearing impairment, $S P_{i}$ indicates social participation, $C V_{i}$ represents the control variables, $\beta_{0}$ suggests the intercept term, $\beta_{1}$ is the coefficient of hearing impairment, $\beta_{2}$ is the coefficient of social participation, $\beta_{3}$ is the coefficient of interaction term between hearing impairment and social participation, which is our main interest, $\beta_{4}$ stands for the coefficients of control variables, $\delta_{s}$ indicates the fixed effects of provinces, and $\varepsilon_{i}$ is the error term. 
Furthermore, we also added the interaction of hearing impairment and exercise to Eq. (1) to explore the moderating effect of exercise on the association between hearing impairment and mental health. The specification of econometric model is as follows:

Mental health ${ }_{i}=\gamma_{0}+\gamma_{1} * \mathrm{HI}_{i}+\gamma_{2} *$ exercise $_{i}+\gamma_{3} * \mathrm{HI}_{i} *$ exercise $_{i}+\gamma_{4} * C V_{i}+\delta_{s}+\varepsilon_{i}$

where $H I_{i}$ denotes hearing impairment, $C V_{i}$ represents the control variables, $\gamma_{0}$ indicates the intercept term, $\gamma_{1}$ is the coefficient of hearing impairment, $\gamma_{2}$ is the coefficient of exercise, $\gamma_{3}$ is the coefficient of interaction term of hearing impairment and exercise, which is our main interest, $\gamma_{4}$ indicates the coefficients of control variables, $\delta_{s}$ indicates the fixed effects of provinces, and $\varepsilon_{i}$ is the error term.

In this study, Stata SE 15.1 software (Stata Corp LP, College Station, TX, USA) was employed to conduct VIF test and descriptive statistics, construct OLS regression and moderated multiple regression models, and perform PSM and doubly robust estimations. Furthermore, all the tests were two-sided and a $p$-value $<0.05$ indicates statistical significance.

\section{Results}

\section{Descriptive Statistics}

Table 1 displays the descriptive statistics. The mean values of MMSE score and depression score were 28.23 and 11.36 , respectively. $22.79 \%$ of the older adults suffered from hearing impairment. Furthermore, more than $19 \%$ of the older adults took part in social activities, and more than $41 \%$ of them participated in exercise. Moreover, more than $74 \%$ of the older adults aged between 65 and 84, and about $54 \%$ of them were male. Approximately $60 \%$ of the older adults were married, and more than $55 \%$ of them lived in urban areas. In addition, the mean values of years of schooling and household income were 4.69 and RMB $30,793.40$ (US\$ 4400.38), respectively. $87.91 \%$ of the older adults were covered by health insurance, and more than $85 \%$ of them had children less than 6 .

\section{OLS Regression Results of the Effect of Hearing Impairment on MMSE Score}

Table 2 displays the OLS regression results of the effect of hearing impairment on MMSE score. According to Model 1, we find that hearing impairment produced a significantly adverse effect on MMSE score (coefficient $=-1.4073, p<0.001)$. We then gradually added the
Table I Descriptive Statistics

\begin{tabular}{|c|c|}
\hline Variables & All $(\mathbf{N}=3721)$ \\
\hline \multicolumn{2}{|l|}{ MMSE score } \\
\hline Mean (SD) & $28.23(2.68)$ \\
\hline \multicolumn{2}{|l|}{ Depression score } \\
\hline Mean (SD) & II.36 (5.92) \\
\hline \multicolumn{2}{|l|}{ Hearing impairment } \\
\hline Without hearing impairment ${ }^{\mathrm{a}}, \mathrm{n}(\%)$ & $2873(77.21)$ \\
\hline With hearing impairment, n (\%) & $848(22.79)$ \\
\hline \multicolumn{2}{|l|}{ Social participation } \\
\hline $\mathrm{No}^{\mathrm{a}}, \mathrm{n}(\%)$ & $3012(80.95)$ \\
\hline Yes, n (\%) & $709(19.05)$ \\
\hline \multicolumn{2}{|l|}{ Exercise } \\
\hline $\mathrm{No}^{\mathrm{a}}, \mathrm{n}(\%)$ & $2180(58.59)$ \\
\hline Yes, n (\%) & $|54|(4|.4|)$ \\
\hline \multicolumn{2}{|l|}{ Age } \\
\hline 65-84, n (\%) & $2765(74.3 I)$ \\
\hline$\geq 85, \mathrm{n}(\%)$ & $956(25.69)$ \\
\hline \multicolumn{2}{|l|}{ Gender } \\
\hline Female $^{\mathrm{a}}, \mathrm{n}(\%)$ & $1706(45.85)$ \\
\hline Male, n (\%) & $2015(54.15)$ \\
\hline \multicolumn{2}{|l|}{ Marital status } \\
\hline Single, divorced or widowed ${ }^{\mathrm{a}}, \mathrm{n}(\%)$ & $1498(40.26)$ \\
\hline Married, n (\%) & $2223(59.74)$ \\
\hline \multicolumn{2}{|l|}{ Residency area } \\
\hline Rural areas ${ }^{\mathrm{a}}, \mathrm{n}(\%)$ & $1642(44.13)$ \\
\hline Urban areas, n (\%) & $2079(55.87)$ \\
\hline \multicolumn{2}{|l|}{ Years of schooling } \\
\hline Mean (SD) & $4.69(4.12)$ \\
\hline \multicolumn{2}{|l|}{ Household income (RMB) } \\
\hline Mean (SD) & $30,793.40(26,468.46)$ \\
\hline \multicolumn{2}{|l|}{ Health insurance } \\
\hline $\mathrm{No}^{\mathrm{a}}, \mathrm{n}(\%)$ & $450(12.09)$ \\
\hline Yes, n (\%) & $327 \mid(87.91)$ \\
\hline \multicolumn{2}{|l|}{ Number of children } \\
\hline $0-5, \mathrm{n}(\%)$ & $3188(85.68)$ \\
\hline$\geq 6, \mathrm{n}(\%)$ & $533(14.32)$ \\
\hline
\end{tabular}

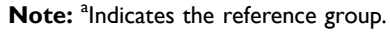

control variables to the Model 1 . When we added the demographic characteristics variables, the coefficient of hearing impairment sharply increased from -1.4073 to -0.7983 , while the regression significance level remained the same (Model 2). When we further added the socioeconomic status and social support variables to Model 3, the regression results show that the coefficient of hearing 
Table 2 OLS Regression Results of the Effect of Hearing Impairment on MMSE Score

\begin{tabular}{|c|c|c|c|}
\hline Variables & Model I & Model 2 & Model 3 \\
\hline Hearing impairment & $\begin{array}{l}-1.4073 * * * \\
(0.1320)\end{array}$ & $\begin{array}{l}-0.7983^{* * * *} \\
(0.1185)\end{array}$ & $\begin{array}{l}-0.7296 * * * \\
(0.1166)\end{array}$ \\
\hline Age & & $\begin{array}{l}-0.0837^{* * * *} \\
(0.0058)\end{array}$ & $\begin{array}{l}-0.0727^{* * *} \\
(0.0065)\end{array}$ \\
\hline Gender & & $\begin{array}{l}0.4465 * * * \\
(0.087 I)\end{array}$ & $\begin{array}{l}0.2023^{*} \\
(0.0884)\end{array}$ \\
\hline Marital status & & $\begin{array}{l}0.1967^{*} \\
(0.0917)\end{array}$ & $\begin{array}{l}0.1381 \\
(0.0909)\end{array}$ \\
\hline Residency area & & $\begin{array}{l}0.3453^{* * * *} \\
(0.0828)\end{array}$ & $\begin{array}{l}0.208 I^{*} \\
(0.0827)\end{array}$ \\
\hline Years of schooling & & & $\begin{array}{l}0.1002 * * * \\
(0.0115)\end{array}$ \\
\hline Household income & & & $\begin{array}{l}0.0806 * * \\
(0.0286)\end{array}$ \\
\hline Health insurance & & & $\begin{array}{l}0.0468 \\
(0.1284)\end{array}$ \\
\hline Number of children & & & $\begin{array}{r}-0.0178 \\
(0.0343)\end{array}$ \\
\hline Constant & $\begin{array}{l}28.6533 * * * \\
(0.2114)\end{array}$ & $\begin{array}{l}34.5756 * * * \\
(0.5074)\end{array}$ & $\begin{array}{l}32.3102 * * * \\
(0.6163)\end{array}$ \\
\hline Dummies for provinces & Control & Control & Control \\
\hline Number of observations & 3721 & 3721 & 3721 \\
\hline F statistics & $8.79 * * *$ & $15.77^{* * *}$ & $16.72 * * *$ \\
\hline R-squared & 0.0703 & 0.1748 & 0.1952 \\
\hline
\end{tabular}

Notes: Robust standard errors are given in parentheses; *** $p<0.001$; ${ }^{* *} p<0.01$; $*_{p}<0.05$.

impairment increased from -0.7983 to -0.7296 . Furthermore, the effect of hearing impairment on MMSE score remained unchanged in terms of regression significance level (Model 3). The regression results imply that compared to the older adults who did not suffer from hearing impairment, those who suffered from hearing impairment had a reduced MMSE score by 0.7296 after adjusting for the control variables.

As expected, the regression results from Model 3 indicate that being older had a significantly negative effect on MMSE score (coefficient $=-0.0727, p<0.001$ ). Furthermore, we obtain evidence indicating that being a male (coefficient $=0.2023, p<0.05$ ), living in urban areas $($ coefficient $=0.2081, p<0.05$ ), having more years of schooling (coefficient $=0.1002, p<0.001$ ) and household income (coefficient $=0.0806, p<0.01$ ) produced significantly positive effects on MMSE score. We also obtain evidence indicating that being married (coefficient $=0.1381, p>0.05)$, having health insurance (coefficient $=$ $0.0468, p>0.05$ ), and number of children (coefficient $=$ $-0.0178, p>0.05)$ exerted no significant effect on MMSE score.

\section{OLS Regression Results of the Effect of Hearing Impairment on Depression Score}

Table 3 shows the OLS regression results of the effect of hearing impairment on depression score. Model 1 shows that hearing impairment had a significantly adverse effect on depression score (coefficient $=0.8682, p<0.001$ ). Furthermore, when we added the demographic characteristics variables to Model 2, the coefficient of hearing impairment increased from 0.8682 to 0.9585 , and the regression significance level remained the same. Then, we further added the socioeconomic status and social support variables to Model 3, with results indicating that the coefficient of hearing impairment decreased from 0.9585 to 0.8795 . In addition, Model 3 also indicates that the effect of hearing impairment on depression score remained unchanged regarding regression significance level. The regression results from Model 3 imply that hearing impairment significantly improved depression score by 0.8795 after adjusting for the control variables.

Regarding the control variables, Model 3 shows that being older (coefficient $=-0.0291, p<0.05$ ), a male (coefficient $=-0.8003, p<0.001$ ), and married (coefficient $=-0.8181, p<0.01)$ produced significantly negative effects on depression score. Furthermore, we also find that having more years of schooling (coefficient $=-0.0713, p<$ 0.05 ) and household income (coefficient $=-0.3955, p<$ 0.001 ) had significantly adverse impacts on depression score. However, we also observe that residency area (coefficient $=0.1751, p>0.05$ ), having health insurance (coefficient $=0.1796, p>0.05)$, and number of children (coefficient $=-0.0649, p>0.05$ ) yielded no significant effect on depression score.

\section{Robustness Checks}

In this section, we used PSM and doubly robust estimation to conduct robustness checks. Firstly, we used k-nearest neighbor matching, radius matching, kernel matching, and nearest-neighbor matching within caliper of the PSM 
Table 3 OLS Regression Results of the Effect of Hearing Impairment on Depression Score

\begin{tabular}{|c|c|c|c|}
\hline Variables & Model I & Model 2 & Model 3 \\
\hline Hearing impairment & $\begin{array}{l}0.8682 * * * \\
(0.2243)\end{array}$ & $\begin{array}{l}0.9585^{* * *} \\
(0.2384)\end{array}$ & $\begin{array}{l}0.8795^{* * *} \\
(0.2380)\end{array}$ \\
\hline Age & & $\begin{array}{l}-0.0267^{*} \\
(0.01 \mathrm{II})\end{array}$ & $\begin{array}{l}-0.029 I^{*} \\
(0.0121)\end{array}$ \\
\hline Gender & & $\begin{array}{l}-0.9799 * * * \\
(0.1945)\end{array}$ & $\begin{array}{l}-0.8003^{* * *} \\
(0.2019)\end{array}$ \\
\hline Marital status & & $\begin{array}{l}-0.9065^{\text {**** }} \\
(0.2232)\end{array}$ & $\begin{array}{l}-0.8181 * * * \\
(0.2217)\end{array}$ \\
\hline Residency area & & $\begin{array}{l}-0.0610 \\
(0.1986)\end{array}$ & $\begin{array}{l}0.175 I \\
(0.2005)\end{array}$ \\
\hline Years of schooling & & & $\begin{array}{c}-0.0713^{*} \\
(0.0280)\end{array}$ \\
\hline Household income & & & $\begin{array}{l}-0.3955^{* * *} \\
(0.0687)\end{array}$ \\
\hline Health insurance & & & $\begin{array}{l}0.1796 \\
(0.2875)\end{array}$ \\
\hline Number of children & & & $\begin{array}{l}-0.0649 \\
(0.0632)\end{array}$ \\
\hline Constant & $\begin{array}{l}8.5697 * * * \\
(0.4878)\end{array}$ & $\begin{array}{l}\text { I I.5583*** } \\
\text { (I.0462) }\end{array}$ & $\begin{array}{l}16.2590 * * * \\
(1.3259)\end{array}$ \\
\hline Dummies for provinces & Control & Control & Control \\
\hline Number of observations & 3721 & 3721 & 3721 \\
\hline F statistics & $18.19 * * *$ & $17.93 * * *$ & $17.06 * * *$ \\
\hline R-squared & 0.1035 & 0.1175 & 0.1303 \\
\hline
\end{tabular}

Notes: Robust standard errors are given in parentheses; $* * * p<0.001 ; *^{*}<0.05$.

method to conduct a robustness check. Table 4 provides the PSM estimation results for the effect of hearing impairment on MMSE score. All of the four matching methods indicate that hearing impairment had a significantly negative effect on MMSE score $(p<0.001)$.

Table 5 reports the PSM estimation results for the effect of hearing impairment on depression score. The estimation results suggest that hearing impairment produced a significantly positive effect on depression score.

Secondly, we used AIPW and IPWRA of doubly robust estimation to conduct a robustness check. Table 6 presents the doubly robust estimation results for the effect of hearing impairment on mental health. AIPW and IPWRA estimators indicate that hearing impairment had significantly negative effects on MMSE score and depression score.

To sum up, the results of the robustness checks lend support to our main finding that hearing impairment produced significantly negative effects on MMSE score and depression score, which suggests that the OLS regression results in the previous sections were highly robust for further research.

\section{Moderating Effects}

Table 7 displays the moderating effects of social participation and exercise on the association between hearing impairment and MMSE score. Models 1 and 2 present the moderating effect of social participation on the association between hearing impairment and MMSE score. Model 1 tested the main effects of hearing impairment and social participation, which suggests that hearing impairment had a significantly negative effect on MMSE score (coefficient $=$ $-0.7290, p<0.001$ ), while social participation produced a significantly positive effect on MMSE score (coefficient $=0.3428, p<0.001$ ). Model 2 tested the moderating effect of social participation on the association between hearing impairment and MMSE score. The results indicate that social participation moderated the association between hearing impairment and MMSE score after adjusting for the control variables (coefficient $=0.9424, p<0.001$ ).

Table 4 PSM Estimation Results for the Effect of Hearing Impairment on MMSE Score

\begin{tabular}{|l|l|l|l|l|l|l|}
\hline Method & Sample & Treated & Control & ATT & S.E. & T-Stat \\
\hline K-nearest neighbor matching & Unmatched & 27.1427 & 28.5503 & -1.4076 & 0.1021 & -13.79 \\
& Matched & 27.1499 & 27.9819 & -0.8320 & 0.1478 & $-5.63 * * *$ \\
\hline Radius matching & Unmatched & 27.1427 & 28.5503 & -1.4076 & 0.1021 & -13.79 \\
& Matched & 27.1499 & 27.9196 & -0.7697 & 0.1402 & $-5.49 * * *$ \\
\hline Kernel matching & Unmatched & 27.1427 & 28.5503 & -1.4076 & 0.1021 & -13.79 \\
& Matched & 27.1499 & 27.9522 & -0.8023 & 0.1397 & $-5.74 * * *$ \\
\hline Nearest-neighbor matching within caliper & Unmatched & 27.1427 & 28.5503 & -1.4076 & 0.1021 & -13.79 \\
& Matched & 27.1499 & 27.9550 & $-0.805 I$ & 0.1479 & $-5.44 * * *$ \\
\hline
\end{tabular}

Note: $* * * p<0.001$. 
Table 5 PSM Estimation Results for the Effect of Hearing Impairment on Depression Score

\begin{tabular}{|c|c|c|c|c|c|c|}
\hline Method & Sample & Treated & Control & ATT & S.E. & T-Stat \\
\hline \multirow[t]{2}{*}{ K-nearest neighbor matching } & Unmatched & 11.8950 & 11.2019 & 0.6932 & 0.2313 & 3.00 \\
\hline & Matched & 11.9032 & 11.1811 & 0.7221 & 0.2764 & $2.61^{*}$ \\
\hline \multirow[t]{2}{*}{ Radius matching } & Unmatched & II.8950 & 11.2019 & 0.6932 & 0.2313 & 3.00 \\
\hline & Matched & 11.9032 & 10.9888 & 0.9143 & $0.26 \mid 4$ & $3.50 * * *$ \\
\hline \multirow[t]{2}{*}{ Kernel matching } & Unmatched & 11.8950 & 11.2019 & 0.6932 & 0.2313 & 3.00 \\
\hline & Matched & 11.9032 & 10.9858 & 0.9173 & 0.2595 & $3.53 * * *$ \\
\hline \multirow[t]{2}{*}{ Nearest-neighbor matching within caliper } & Unmatched & II.8950 & 11.2019 & 0.6932 & 0.2313 & 3.00 \\
\hline & Matched & 11.9032 & 11.1690 & 0.7342 & 0.2767 & $2.65^{*}$ \\
\hline
\end{tabular}

Notes: $* * * p<0.001 ; *_{p}<0.05$

Table 6 Doubly Robust Estimation Results for the Effect of Hearing Impairment on Mental Health

\begin{tabular}{|l|l|l|l|l|}
\hline \multirow{2}{*}{} & \multicolumn{2}{l}{ MMSE Score } & \multicolumn{2}{l|}{ Depression Score } \\
\cline { 2 - 5 } & Model I & Model 2 & Model 3 & Model 4 \\
\cline { 2 - 5 } & AIPW & IPWRA & AIPW & IPWRA \\
\hline ATE & $\begin{array}{l}-0.5904^{* * *} \\
(0.1044)\end{array}$ & $\begin{array}{l}-0.5829 * * * \\
(0.1025)\end{array}$ & $\begin{array}{l}0.636 I^{*} \\
(0.2762)\end{array}$ & $\begin{array}{l}0.6239^{*} \\
(0.2740)\end{array}$ \\
\hline POmean & $28.4159^{* * *}$ & $28.4160^{* * *}$ & $11.2077^{* * *}$ & $\begin{array}{l}11.2076 * * * \\
(0.1105)\end{array}$ \\
\hline ATT & $(0.0467)$ & $(0.0467)$ & & $0.1106)$ \\
\hline POmean & & $-0.8200^{* * * *}$ & & $(0.2507)$ \\
\hline Observations & & $(0.1398)$ & & $\begin{array}{l}11.2246 * * * \\
(0.1469)\end{array}$ \\
\hline
\end{tabular}

Notes: Robust standard errors are given in parentheses; ${ }^{* * *} p<0.001$; ${ }^{* *} p<0.01$; ${ }^{*} p<0.05$.

Specifically speaking, social participation relieved the negative effect of hearing impairment on MMSE score. This implies that hearing impairment had a significantly weaker impact on the cognitive function of older adults who participated in social activities than those who did not.

Models 3 and 4 of Table 7 report the moderating effect of exercise on the association between hearing impairment and MMSE score. Model 3 displays the main effects of hearing impairment and exercise, which indicates that hearing impairment produced a significantly negative effect on MMSE score (coefficient $=-0.7275, p<$ 0.001 ), while exercise yielded a significantly positive effect on MMSE score (coefficient $=0.2120, p<0.01$ ). Model 4 presents the moderating effect of exercise on the association between hearing impairment and MMSE score, with regression results indicating that exercise moderated the association between hearing impairment and MMSE score after adjusting for the control variables (coefficient $=$ $0.7001, p<0.01)$. More specifically, exercise relieved the adverse effect of hearing impairment on MMSE score, which implies that hearing impairment produced a significantly weaker effect on the cognitive function of older adults who participated in exercise than those who did not.

Table 8 presents the moderating effects of social participation and exercise on the association between hearing impairment and depression score. Models 1 and 2 show the moderating effect of social participation on the association between hearing impairment and depression score. Model 1 explored the main effects of hearing impairment and social participation, which reveals that hearing impairment had a significantly positive effect on depression score 
Table 7 Moderating Effects of Social Participation and Exercise on the Association Between Hearing Impairment and MMSE Score

\begin{tabular}{|c|c|c|c|c|}
\hline Variables & Model I & Model 2 & Model 3 & Model 4 \\
\hline Hearing impairment & $\begin{array}{l}-0.7290 * * * \\
(0.1164)\end{array}$ & $\begin{array}{l}-0.8788^{* * * *} \\
(0.1327)\end{array}$ & $\begin{array}{l}-0.7275 * * * \\
(0.1164)\end{array}$ & $\begin{array}{l}-1.0087 * * * \\
(0.1674)\end{array}$ \\
\hline Social participation & $\begin{array}{l}0.3428 * * * \\
(0.0896)\end{array}$ & $\begin{array}{l}0.1623 \\
(0.0910)\end{array}$ & & \\
\hline Exercise & & & $\begin{array}{l}0.2120 * * \\
(0.0799)\end{array}$ & $\begin{array}{l}0.0546 \\
(0.0807)\end{array}$ \\
\hline Age & $\begin{array}{l}-0.0712^{* * * *} \\
(0.0065)\end{array}$ & $\begin{array}{l}-0.0710 * * * \\
(0.0065)\end{array}$ & $\begin{array}{l}-0.0719 * * * \\
(0.0065)\end{array}$ & $\begin{array}{l}-0.0712^{* * *} \\
(0.0064)\end{array}$ \\
\hline Gender & $\begin{array}{l}0.2074^{*} \\
(0.0882)\end{array}$ & $\begin{array}{l}0.2108 * \\
(0.088 \mathrm{I})\end{array}$ & $\begin{array}{l}0.2044^{*} \\
(0.0884)\end{array}$ & $\begin{array}{l}0.2010 * \\
(0.0883)\end{array}$ \\
\hline Marital status & $\begin{array}{l}0.1400 \\
(0.0908)\end{array}$ & $\begin{array}{l}0.1314 \\
(0.0909)\end{array}$ & $\begin{array}{l}0.1429 \\
(0.0911)\end{array}$ & $\begin{array}{l}0.1363 \\
(0.0908)\end{array}$ \\
\hline Residency area & $\begin{array}{l}0.1933^{*} \\
(0.0827)\end{array}$ & $\begin{array}{l}0.1965^{*} \\
(0.0826)\end{array}$ & $\begin{array}{l}0.1872^{*} \\
(0.0830)\end{array}$ & $\begin{array}{l}0.1932 * \\
(0.0830)\end{array}$ \\
\hline Years of schooling & $\begin{array}{l}0.0953^{* * *} \\
(0.0116)\end{array}$ & $\begin{array}{l}0.0965 * * * \\
(0.0116)\end{array}$ & $\begin{array}{l}0.0964 * * * \\
(0.0117)\end{array}$ & $\begin{array}{l}0.0968 * * * \\
(0.0117)\end{array}$ \\
\hline Household income & $\begin{array}{l}0.0777 * * \\
(0.0286)\end{array}$ & $\begin{array}{l}0.0785 * * \\
(0.0286)\end{array}$ & $\begin{array}{l}0.0779 * * \\
(0.0285)\end{array}$ & $\begin{array}{l}0.0804 * * \\
(0.0284)\end{array}$ \\
\hline Health insurance & $\begin{array}{l}0.0471 \\
(0.128 I)\end{array}$ & $\begin{array}{l}0.0473 \\
(0.1280)\end{array}$ & $\begin{array}{l}0.0569 \\
(0.1283)\end{array}$ & $\begin{array}{l}0.0426 \\
(0.1278)\end{array}$ \\
\hline Number of children & $\begin{array}{l}-0.0144 \\
(0.0343)\end{array}$ & $\begin{array}{l}-0.0139 \\
(0.0342)\end{array}$ & $\begin{array}{l}-0.0195 \\
(0.0343)\end{array}$ & $\begin{array}{l}-0.0206 \\
(0.034 I)\end{array}$ \\
\hline $\begin{array}{l}\text { Hearing impairment } * \\
\text { Social participation }\end{array}$ & & $\begin{array}{l}0.9424 * * * \\
(0.2477)\end{array}$ & & \\
\hline $\begin{array}{l}\text { Hearing impairment } * \\
\text { Exercise }\end{array}$ & & & & $\begin{array}{l}0.700 I^{* *} \\
(0.2278)\end{array}$ \\
\hline Constant & $\begin{array}{l}32.1156^{* * *} \\
(0.6193)\end{array}$ & $\begin{array}{l}32.1286 * * * \\
(0.6172)\end{array}$ & $\begin{array}{l}32.1819 * * * \\
(0.6097)\end{array}$ & $\begin{array}{l}32.1929 * * * \\
(0.6072)\end{array}$ \\
\hline Dummies for provinces & Control & Control & Control & Control \\
\hline Number of observations & 3721 & 3721 & 3721 & 3721 \\
\hline F statistics & $16.94^{* * *}$ & $|6.6|^{* * *}$ & $16.23 * * *$ & $16.03 * * *$ \\
\hline R-squared & 0.1973 & 0.2002 & 0.1966 & 0.1994 \\
\hline
\end{tabular}

Notes: Robust standard errors are given in parentheses; ${ }^{* * *} p<0.001 ;{ }^{* *} p<0.01 ; *^{*}<0.05$

(coefficient $=0.8784, p<0.001$ ), whilst social participation produced a significantly adverse effect on depression score (coefficient $=-0.6105, p<0.05$ ). Model 2 shows that the interaction term between hearing impairment and social participation was not statistically significant (coefficient $=-0.5991, p>0.05)$, which indicates that social participation did not moderate the association between hearing impairment and depression score after adjusting for the control variables.

Models 3 and 4 of Table 8 present the moderating effect of exercise on the association between hearing impairment and depression score. Model 3 tested the main effects of hearing impairment and exercise, indicating that hearing impairment had a significantly positive effect on depression 
Table 8 Moderating Effects of Social Participation and Exercise on the Association Between Hearing Impairment and Depression Score

\begin{tabular}{|c|c|c|c|c|}
\hline Variables & Model I & Model 2 & Model 3 & Model 4 \\
\hline Hearing impairment & $\begin{array}{l}0.8784 * * * \\
(0.2375)\end{array}$ & $\begin{array}{l}0.9737^{* * *} \\
(0.2573)\end{array}$ & $\begin{array}{l}0.8667^{* * * *} \\
(0.2370)\end{array}$ & $\begin{array}{l}0.5532 \\
(0.2952)\end{array}$ \\
\hline Social participation & $\begin{array}{l}-0.6105^{*} \\
(0.2459)\end{array}$ & $\begin{array}{l}-0.4957 \\
(0.2716)\end{array}$ & & \\
\hline Exercise & & & $\begin{array}{l}-1.2822^{* * *} \\
(0.1918)\end{array}$ & $\begin{array}{l}-1.4578 * * * \\
(0.2145)\end{array}$ \\
\hline Age & $\begin{array}{l}-0.0316^{* *} \\
(0.0121)\end{array}$ & $\begin{array}{l}-0.0318 * * \\
(0.0121)\end{array}$ & $\begin{array}{l}-0.0337^{* *} \\
(0.0120)\end{array}$ & $\begin{array}{l}-0.0330 * * \\
(0.0120)\end{array}$ \\
\hline Gender & $\begin{array}{l}-0.8094^{* * *} \\
(0.2017)\end{array}$ & $\begin{array}{l}-0.8116^{* * *} \\
(0.2015)\end{array}$ & $\begin{array}{l}-0.8132^{* * *} \\
(0.2004)\end{array}$ & $\begin{array}{l}-0.8170 * * * \\
(0.2004)\end{array}$ \\
\hline Marital status & $\begin{array}{l}-0.8215^{* * *} \\
(0.2220)\end{array}$ & $\begin{array}{l}-0.8161^{* * *} \\
(0.2220)\end{array}$ & $\begin{array}{l}-0.847 I^{* * *} \\
(0.2216)\end{array}$ & $\begin{array}{l}-0.8544 * * * \\
(0.2215)\end{array}$ \\
\hline Residency area & $\begin{array}{l}0.2014 \\
(0.2003)\end{array}$ & $\begin{array}{l}0.1993 \\
(0.2003)\end{array}$ & $\begin{array}{l}0.3012 \\
(0.2006)\end{array}$ & $\begin{array}{l}0.3080 \\
(0.2006)\end{array}$ \\
\hline Years of schooling & $\begin{array}{l}-0.0626^{*} \\
(0.028 \mathrm{I})\end{array}$ & $\begin{array}{l}-0.0633^{*} \\
(0.028 \mathrm{I})\end{array}$ & $\begin{array}{l}-0.0485 \\
(0.0278)\end{array}$ & $\begin{array}{l}-0.048 \mathrm{I} \\
(0.0278)\end{array}$ \\
\hline Household income & $\begin{array}{l}-0.3904^{* * *} \\
(0.0687)\end{array}$ & $\begin{array}{l}-0.3909 * * * \\
(0.0687)\end{array}$ & $\begin{array}{l}-0.3792^{* * *} \\
(0.0684)\end{array}$ & $\begin{array}{l}-0.3764 * * * \\
(0.0685)\end{array}$ \\
\hline Health insurance & $\begin{array}{l}0.1790 \\
(0.2865)\end{array}$ & $\begin{array}{l}0.1789 \\
(0.2866)\end{array}$ & $\begin{array}{l}0.1185 \\
(0.2854)\end{array}$ & $\begin{array}{l}0.1024 \\
(0.2860)\end{array}$ \\
\hline Number of children & $\begin{array}{l}-0.0710 \\
(0.0631)\end{array}$ & $\begin{array}{l}-0.0713 \\
(0.0631)\end{array}$ & $\begin{array}{l}-0.0549 \\
(0.0633)\end{array}$ & $\begin{array}{l}-0.0561 \\
(0.0632)\end{array}$ \\
\hline $\begin{array}{l}\text { Hearing impairment * } \\
\text { Social participation }\end{array}$ & & $\begin{array}{l}-0.5991 \\
(0.606 I)\end{array}$ & & \\
\hline $\begin{array}{l}\text { Hearing impairment } * \\
\text { Exercise }\end{array}$ & & & & $\begin{array}{l}0.7806 \\
(0.4558)\end{array}$ \\
\hline Constant & $\begin{array}{l}16.6057^{* * *} \\
(1.3279)\end{array}$ & $\begin{array}{l}16.5974 * * * \\
(1.3280)\end{array}$ & $\begin{array}{l}17.0346 * * * \\
(I .324 I)\end{array}$ & $\begin{array}{l}17.0468 * * * \\
(1.3244)\end{array}$ \\
\hline Dummies for provinces & Control & Control & Control & Control \\
\hline Number of observations & 3721 & 3721 & 3721 & 3721 \\
\hline F statistics & $16.92 * * *$ & $16.47^{* * *}$ & $|8.8| * * *$ & $18.36 * * *$ \\
\hline R-squared & 0.1317 & 0.1320 & 0.1406 & 0.1413 \\
\hline
\end{tabular}

Notes: Robust standard errors are given in parentheses; ***p $<0.001 ; * * p<0.01 ; * p<0.05$.

score (coefficient $=0.8667, p<0.001$ ), while exercise produced a significantly negative effect on depression score (coefficient $=-1.2822, p<0.001)$. Model 4 shows that the interaction term between hearing impairment and exercise was statistically insignificant (coefficient $=0.7806, p>0.05$ ), which suggests that exercise did not moderate the association between hearing impairment and depression score after adjusting for the control variables. 


\section{Discussion}

Using the 2018 wave of CLHLS dataset, we examined the effect of hearing impairment on mental health among the Chinese older adults. We used PSM and doubly robust estimation to conduct robustness checks. The results of this study indicate that hearing impairment had a significantly negative effect on the cognitive function of older adults. This is consistent with the findings of previous studies. ${ }^{4,6,16}$ Furthermore, we obtain robust evidence indicating that hearing impairment produced a negative effect on the depression status of older adults, which is consistent with the findings of Strawbridge et al. ${ }^{17}$ Keidser and Seeto, ${ }^{18}$ and Ye et al. ${ }^{19}$ However, this finding is not consistent with $\mathrm{Hu}$ et $\mathrm{al}^{20}$ and Zhou et al. ${ }^{21}$ This inconsistency may be due to various reasons, such as using different measurements of depression status.

We also investigated whether social participation and exercise moderated the association between hearing impairment and mental health among the older adults. Our findings suggest that social participation relieved the negative effect of hearing impairment on cognitive function. This finding is consistent with Gao et $\mathrm{al}^{41}$ who also reported that frequent engagement in leisure activities moderated the association between hearing impairment and cognitive decline for the Chinese older adults. Our findings also suggest that exercise relieved the negative effect of hearing impairment on cognitive function. However, there is no evidence indicating that social participation relieved the adverse effect of hearing impairment on depression status of the older adults. Furthermore, it is found that exercise did not relieve the adverse effect of hearing impairment on depression status.

This study has rich policy implications. Firstly, it is reasonable to pay more attention to the mental health of older adults with hearing impairment. Furthermore, family members should frequently talk to the older adults with hearing impairment to avoid social isolation. Secondly, the government ought to encourage the older adults with hearing impairment to frequently participate in social activities. Thirdly, it is necessary for the government to encourage the older adults with hearing impairment to actively take part in exercise. Finally, the government needs to provide more care and assistance for the hearingimpaired older adults who can not participate in social activities or exercise due to physical disabilities.

This study has several strengths. Firstly, to the best of our knowledge, this is the first study that used PSM and doubly robust estimation to investigate the effect of hearing impairment on mental health in a nationally representative Chinese older adults setting. Secondly, this is the first study to explore the moderating effects of social participation and exercise on the association between hearing impairment and depression status among Chinese older adults. Thirdly, this study provides important empirical evidence for the construction of healthy aging in China. In addition, this study highlights the importance of social participation and exercise in alleviating the adverse effect of hearing impairment on cognitive function for older adults.

While this study offers a rigorous examination of the effect of hearing impairment on mental health among the older adults, it has several shortcomings. Firstly, the measurement of hearing impairment is based on self-reports, which may lead to measurement bias. Future studies may consider using a strict audiometry to fix this problem. Secondly, due to the unavailability of data, we cannot investigate the effects of duration and severity of hearing impairment on mental health among the older adults. Future studies may consider exploring these effects when more data are available. Thirdly, even though we have explored the moderating effects of social participation and exercise on the association between hearing impairment and mental health among older adults, other moderating effects on this association may still exist. Future studies may consider exploring other moderating effects on the association between hearing impairment and mental health among older adults.

\section{Conclusions}

In conclusion, we provide robust evidence indicating that hearing impairment had significantly negative effects on the cognitive function and depression status of older adults. Furthermore, we find that social participation and exercise relieved the negative effect of hearing impairment on cognitive function. Moreover, there is no evidence indicating that social participation or exercise relieved the adverse effect of hearing impairment on depression status.

\section{Abbreviations}

CLHLS, Chinese Longitudinal Healthy Longevity Survey; MMSE, Mini-Mental State Examination; VIF, variance inflation factor; OLS, ordinary least squares; PSM, propensity score matching; AIPW, augmented inverse-probability weighting; IPWRA, inverse-probability-weighted regression adjustment. 


\section{Ethical Statement}

The study received ethical approval from the Review Board of Guangxi Medical University. The data which was used in this study are secondary data. We have got the permission to use the database from the Chinese Longitudinal Healthy Longevity Survey (CLHLS) team. The CLHLS has obtained the ethical approval and informed consent, and was approved by research ethics committees of Peking University. In addition, the data which were used in this study were anonymised before use.

\section{Acknowledgment}

The authors would like to acknowledge the Chinese Longitudinal Healthy Longevity Survey (CLHLS) team for providing data. In addition, this study was funded by China Scholarship Council (202006230342) and CMB-OC (2014-203).

\section{Disclosure}

The authors report no conflicts on interest in this work.

\section{References}

1. Yu L, Sun X, Wei Z, et al. A study on the status quo of aged population with hearing loss in China. Chin Sci J Hear Speech Rehabilit. 2008;6(3):63-65.

2. Ciorba A, Bianchini C, Pelucchi S, et al. The impact of hearing loss on the quality of life of elderly adults. Clin Interv Aging. 2012;7:159-163. doi:10.2147/CIA.S26059

3. Ogawa T, Uchida Y, Nishita Y, et al. Hearing-impaired elderly people have smaller social networks: a population-based aging study. Arch Gerontol Geriatr. 2019;83:75-80. doi:10.1016/j.archger.2019.03.004

4. Dalton DS, Cruickshanks KJ, Klein BE, et al. The impact of hearing loss on quality of life in older adults. Gerontologist. 2003;43 (5):661-668. doi:10.1093/geront/43.5.661

5. Chia EM, Wang JJ, Rochtchina E, et al. Hearing impairment and health-related quality of life: the blue mountains hearing study. Ear Hear. 2007;28(2):187-195. doi:10.1097/AUD.0b013e31803126b6

6. Gao J, Armstrong NM, Deal JA, et al. Hearing loss and cognitive function among Chinese older adults: the role of participation in leisure activities. BMC Geriatr. 2020;20(1):215. doi:10.1186/ s12877-020-01615-7

7. Gopinath B, Schneider JA, Mcmahon CM, et al. Severity of age-related hearing loss is associated with impaired activities of daily living. Age Ageing. 2012;41(2):195-200. doi:10.1093/ageing/ afr 155

8. Ye X, Zhu D, Chen S, et al. The association of hearing impairment and its severity with physical and mental health among Chinese middle-aged and older adults. Health Qual Life Outcomes. 2020;18 (1):155. doi:10.1186/s12955-020-01417-w

9. Arlinger S. Negative consequences of uncorrected hearing loss-a review. Int $J$ Audiol. 2003;42(2):S17-S20. doi:10.3109/ 14992020309074639

10. Appollonio I, Carabellese C, Frattola L, et al. Effects of sensory aids on the quality of life and mortality of elderly people: a multivariate analysis. Age Ageing. 1996;25(2):89-96. doi:10.1093/ageing/25.2.89
11. National Bureau of Statistics of China. China Statistical Yearbook. Beijing: China Statistics Press; 2019.

12. China National Research Group on Population Aging Strategy. The National Research Report on the Strategy of Population Aging. Beijing: Hua Ling Press of China; 2014.

13. Feng Y, Wu B. Aging and Global Health. Beijing: People's Medical Publishing House; 2018.

14. Wen X, Wen F, Ye L. The effects of social capital on mental health of the Chinese rural elderly: an analysis based on survey data from the China health and retirement longitudinal study. Chin Rural Surv. 2017;38(4):130-144.

15. Zeng Q, Chen C. Elderly Health Service and Management. Beijing: People's Medical Publishing House; 2020.

16. Tan W, Chen G. Relationship between visual function, hearing function and cognitive function in elderly Chinese: introduce depression and social activities as mediation. Popul Dev. 2020;26(2):70-78.

17. Strawbridge WJ, Wallhagen MI, Shema SJ, et al. Negative consequences of hearing impairment in old age a longitudinal analysis. Gerontologist. 2000;40(3):320-326. doi:10.1093/geront/40.3.320

18. Keidser G, Seeto M. The Influence of social interaction and physical health on the association between hearing and depression with age and gender. Trends Hear. 2017;21:1-15. doi:10.1177/ 2331216517706395

19. Ye X, Zhu D, Gao J, et al. The impact of hearing on the depression of older Chinese adults. Popul Dev. 2019;25(5):66-74.

20. Hu Z, Qin X, Xu X, et al. The prevalence of the elderly somatic disease and elderly depression. Chin Prim Health Care. 2004;18 (4):36-38

21. Zhou C, Xu X, Ma S, et al. Analysis of the prevalence of somatic diseases and depression among the elderly. Chin J Public Health. 2006;22(7):871-872.

22. Haslam C, Cruwys T, Haslam SA. "The we's have it": evidence for the distinctive benefits of group engagement in enhancing cognitive health in aging. Soc Sci Med. 2014;120:57-66. doi:10.1016/j. socscimed.2014.08.037

23. Croezen S, Avendano M, Burdorf A, et al. Social participation and depression in old age: a fixed-effects analysis in 10 European countries. Am J Epidemiol. 2015;182(2):168-176. doi:10.1093/aje/kwv015

24. Lee Y, Yeung WJJ. Gender matters: productive social engagement and the subsequent cognitive changes among older adults. Soc Sci Med. 2019;229:87-95. doi:10.1016/j.socscimed.2018.08.024

25. Stephens T. Physical activity and mental health in the United States and Canada: evidence from four popular surveys. Prev Med. 1988;17 (1):35-47. doi:10.1016/0091-7435(88)90070-9

26. Farmer ME, Locke BZ, Mosciki EK, et al. Physical activity and depressive symptoms: the NHANES I epidemiologic follow-up study. Am J Epidemiol. 1988;128:1340-1351. doi:10.1093/oxfordjournals.aje.a115087

27. Steptoe A, Butler N. Sports participation and emotional wellbeing in adolescents. Lancet. 1996;347:1789-1792. doi:10.1016/S01406736(96)91616-5

28. Dunn AL, Jewell JS. The effect of exercise on mental health. Curr Sports Med Rep. 2010;9(4):202-207. doi:10.1249/JSR.0b013e3181e7d9af

29. Yi Z, Vaupel JW, Zhenyu X, et al. Sociodemographic and health profiles of the oldest old In China. Popul Dev Rev. 2002;28 (2):251-273. doi:10.1111/j.1728-4457.2002.00251.x

30. Folstein MF, Folstein S, Mchugh PR. "Mini-mental state". A practical method for grading the cognitive state of patients for the clinician. J Psychiatr Res. 1975;12(3):189-198. doi:10.1016/ 0022-3956(75)90026-6

31. Zhang Z, Gu D, Hayward MD. Early life influences on cognitive impairment among oldest old Chinese. J Gerontol B Psychol Sci Soc Sci. 2008;63(1):S25-S33. doi:10.1093/geronb/63.1.S25

32. Gao M, Li Y, Zhang S, et al. Does an empty nest affect elders' health? Empirical evidence from China. Int J Environ Res Public Health. 2017;14(5):463. doi:10.3390/ijerph14050463 
33. Li LW, Liu J, Xu H, et al. Understanding rural-urban differences in depressive symptoms among older adults in China. J Aging Health. 2016;28(2):341-362. doi:10.1177/0898264315591003

34. Xu Y, Yang J, Gao J, et al. Decomposing socioeconomic inequalities in depressive symptoms among the elderly in China. BMC Public Health. 2016;16(1):1214. doi:10.1186/s12889-016-3876-1

35. Rosenbaum PR, Rubin DB. Constructing a control group using multivariate matched sampling methods that incorporate the propensity score. Am Stat. 1985;39(1):33-38.

36. Heckman JJ, Ichimura $\mathrm{H}$, Todd PE, et al. Matching as an econometric evaluation estimator: evidence from evaluating a job training programme. Rev Econ Stud. 1997;64(4):605-654. doi:10.2307/ 2971733

37. Zhao X. Propensity score matching: issues on covariates choice and model specification. J Quant Tech Econ. 2015;32(11):133-147.
38. $\mathrm{Hu}$ A. Applied Statistical Causal Inference. Shanghai: Fudan University Press; 2020.

39. Hall CE, Steiner PM, Kim JS. Doubly robust estimation of treatment effects from observational multilevel data. In: van der Ark L, Bolt D, Wang WC, et al. editors. Quantitative Psychology Research. Springer Proceedings in Mathematics \& Statistics Vol. 140. Cham: Springer; 2015.

40. Funk MJ, Westreich D, Wiesen C, et al. Doubly robust estimation of causal effects. Am J Epidemiol. 2011;173(7):761-767. doi:10.1093/ aje/kwq439

41. Gao J, Hu H, Yao L. The role of social engagement in the association of self-reported hearing loss and health-related quality of life. $B M C$ Geriatr. 2020;20(1):182. doi:10.1186/s12877-020-01581-0
Risk Management and Healthcare Policy

\section{Publish your work in this journal}

Risk Management and Healthcare Policy is an international, peerreviewed, open access journal focusing on all aspects of public health, policy, and preventative measures to promote good health and improve morbidity and mortality in the population. The journal welcomes submitted papers covering original research, basic science, clinical \& epidemiological studies, reviews and evaluations,

\section{Dovepress}

guidelines, expert opinion and commentary, case reports and extended reports. The manuscript management system is completely online and includes a very quick and fair peer-review system, which is all easy to use. Visit http://www.dovepress.com/testimonials.php to read real quotes from published authors. 